\title{
Huge cervical pedunculated leiomyoma with uterine prolapse: a case report
}

\author{
Shweta Avinash Khade*, Balaji Jadhav, Rohini Raut
}

Department of Obstetrics and Gynecology, BYL TNMC, Mumbai Central, Maharashtra, India

Received: 19 February 2018

Revised: 12 August 2018

Accepted: 07 January 2019

\section{*Correspondence:}

Dr. Shweta Avinash Khade,

E-mail: drshwetam2009@gmail.com

Copyright: $\odot$ the author(s), publisher and licensee Medip Academy. This is an open-access article distributed under the terms of the Creative Commons Attribution Non-Commercial License, which permits unrestricted non-commercial use, distribution, and reproduction in any medium, provided the original work is properly cited.

\begin{abstract}
Leiomyoma uterus is the most common benign solid tumor in female. Most of it situated in the body of the uterus. cervical myoma account 3\%-8\% of uterine myoma. Cervical myoma can frequently cause diagnostic dilemmas. Pedunculated cervical myoma can arise from the endocervical canal or from the uterine cavity and protrude through the cervix, may become necrotic, infected and gangrenous due to inadequate blood circulation through a long pedicle or if the pedicle of leiomyoma twists. This can cause menometrorrhagia, recurrent vaginal discharge leading to anemia and sepsis. A case of huge pedunculated cervical leiomyoma has been reported here. A 40 years old female, para 4, with menometrorrhagia, excessive vaginal discharge and severe anemia with haemoglobin $5 \mathrm{gm} \%$ and challenging huge cervical pedunculated leiomyoma of size $13 \mathrm{~cm} * 9 \mathrm{~cm} * 9 \mathrm{~cm}$ prolapsed outside introitus which is congested necrotic, infected causing uterine prolapse with bilateral hydroureter and hydronephrosis. Patient underwent bilateral internal iliac artery ligation and fibroid excision followed by total abdominal hysterectomy with bilateral salpingectomy after tracing both ureters. Post-operative period was uneventful. Histopathology was confirmatory of leiomyoma.
\end{abstract}

Keywords: Abdominal hysterectomy, Pedunculated cervical leiomyoma, Prolapse uterus

\section{INTRODUCTION}

Uterine fibroids are the most common tumours of uterus which develop in $20-40 \%$ of reproductive age women, but cervical leiomyomas are less than $5 \%$ of all leiomyomas. ${ }^{1}$ Cervical leiomyoma is uncommon and only $1-2 \%$ are confined to cervix. ${ }^{1}$ There are three types of cervical fibroid, namely interstitial, supramarginal and polypoidal, of these types, the polypoidal is rare. ${ }^{2}$ Cervical fibroid polyp usually arises from the ectocervix and from its posterior lip. ${ }^{3}$ It may be small and usually single. At times, it is big enough to distend the vagina or even comes out of the introitus, confusing the diagnosis of uterine inversion. ${ }^{3}$ This tumor can frequently present with heaviness in the vagina, mass in the vagina, sensation of something coming down when the polyp becomes big distending the vagina, descent of uterus, excessive vaginal discharge which may be offensive. ${ }^{3}$ Pedunculated uterine myomas or submucosal cervical myomas may protrude through the cervical canal and into the vagina and may become necrotic and occasionally infected due to inadequate blood supply. ${ }^{3}$ Here reporting a case of huge cervical pedunculated leiomyoma.

\section{CASE REPORT}

Mrs. 'X' 45 years, widow, parity-4, living 2, last child birth 13 years back, tubal ligation done. From low socioeconomic condition, from tribal area, referred as inversion from peripheral hospital came in emergency, 
with the complaints of a sudden protrusion of large mass through introitus for 2 days. Careful history revealed that for 2 years she had complaint of something coming out of vagina, occasionally protruding to the introitus and receding spontaneously. Along with lower abdominal pain and dragging sensation and on and off blood mixed foul-smelling discharge per vaginum. she had irregular and heavy menstrual bleeding. she had complaint of difficulty in passing urine for 6 months.

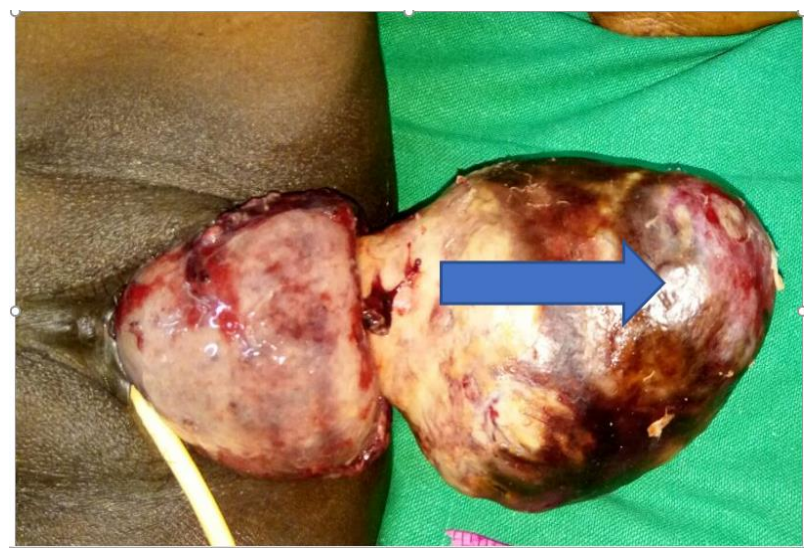

Figure 1: Pedunculated cervical leiomyoma protruding through introitus.

On examination, patient was in agony, dehydrated with severe pallor. Her pulse rate 100/minute and BP110/70mmhg. Systemic examination was within normal limits. On per abdomen examination, it was soft, nontender and no palpable organomegaly. On local examination, $13 * 9 * 7 \mathrm{~cm}$ fleshy mass seen protruded through vagina and hanging outside the introitus (Figure 1), non-reducible, irregular surface, firm in consistency, congested with areas of slough and necrosis associated with bleeding per vaginum cervix was congested, thickened, engorged in size. On per vaginal examination, cervical rim was felt encircling the mass.

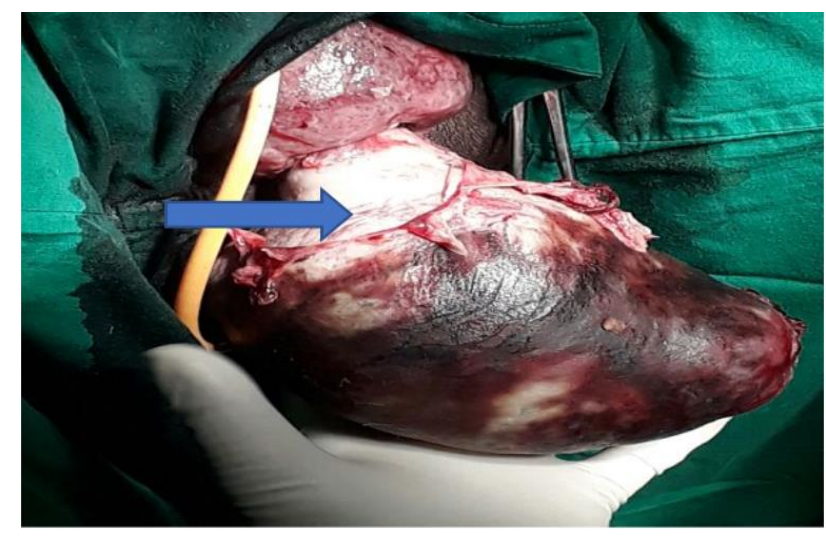

Figure 2: Thick pedicle arising from posterior side of endocervix.

Thick pedicle (Figure 2) was arising from posterior lip of cervix with second degree uterine prolapse bleeding per vaginum present. CT scan revealed descent of uterus $7 \mathrm{~cm}$ below pubococcygeal line suggestive of uterine prolapse. well defined homogenously enhancing mass lesion $13 * 9 * 9 \mathrm{~cm}$ noted arising from cervix and extending externally outside through vaginal introitus suggestive of fibroid descent. bilateral moderate hydronephrosis and hydroureter seen.

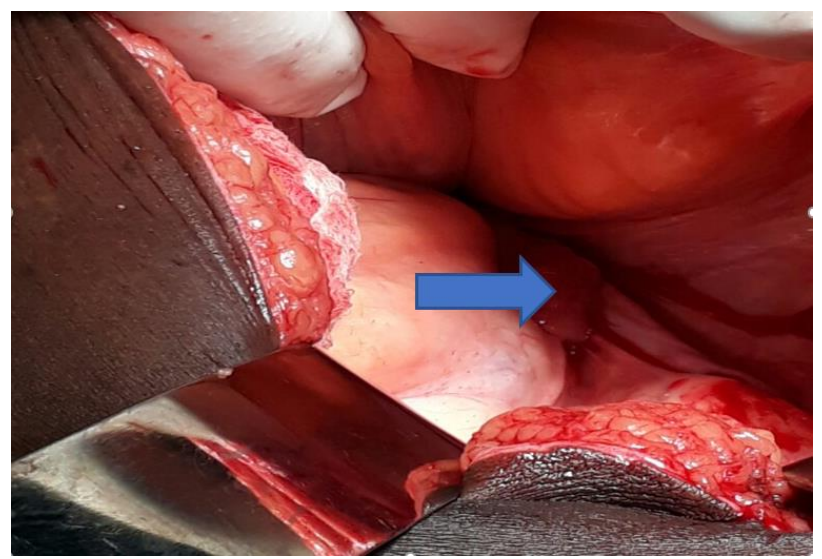

Figure 3: Intraoperative abdominally uterus and adnexa are pulled down due to huge fibroid.

The patient was kept on broad spectrum antibiotics, iv fluids, analgesics and frequent vulval toileting with antiseptic and saline irrigation of the mass. She was prepared for operation; all preoperative investigations were found normal except $\mathrm{Hb} \%$ which was $5 \mathrm{gm} / \mathrm{dl} .{ }^{3} \mathrm{PCV}$ transfused pre-operatively.to manage this case there were two difficulties: patient had severe anemia, hydroureter and hydronephrosis. In operation theater, under general anesthesia, decision of abdomin-vaginal approach is taken. Midline infra umbilical vertical incision is taken. Abdominally uterus and adnexa were pulled down due to traction exerted by cervical fibroid (Figure 3).

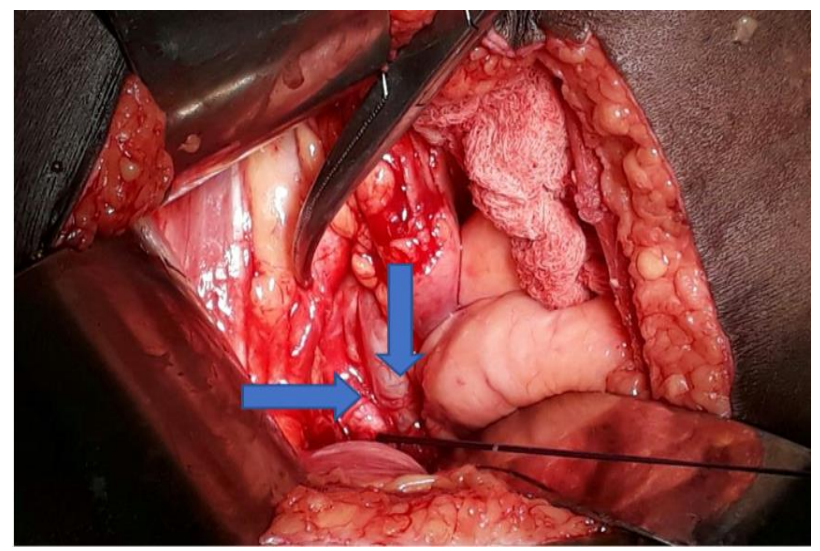

Figure 4: Retroperitoneum dissection showing right sided internal iliac artery and hydroureter.

As patient was already severe anemic, to prevent further blood loss during surgery first bilateral internal iliac arteries (Figure 4) were ligated, then cervical pedunculated fibroid excision is done vaginally (Figure 5 and 6). 


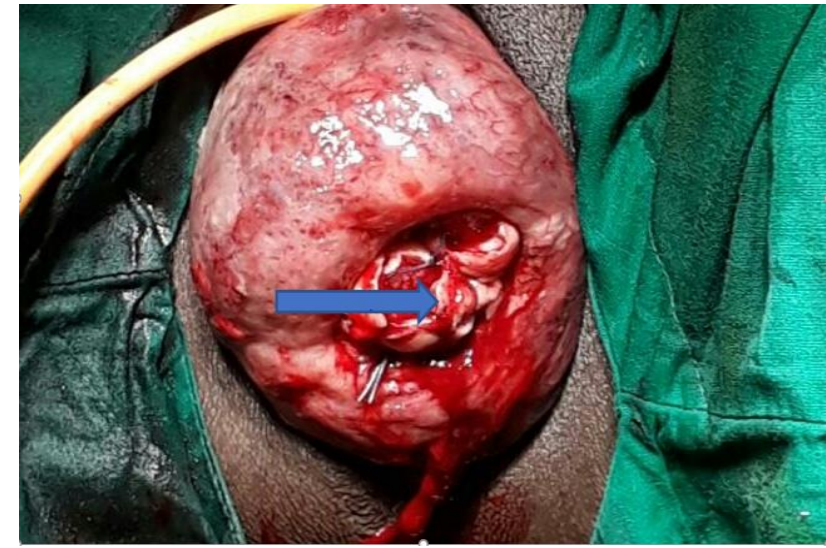

Figure 5: Engorged and congested cervix after excision and trans fixation of fibroid pedicle.

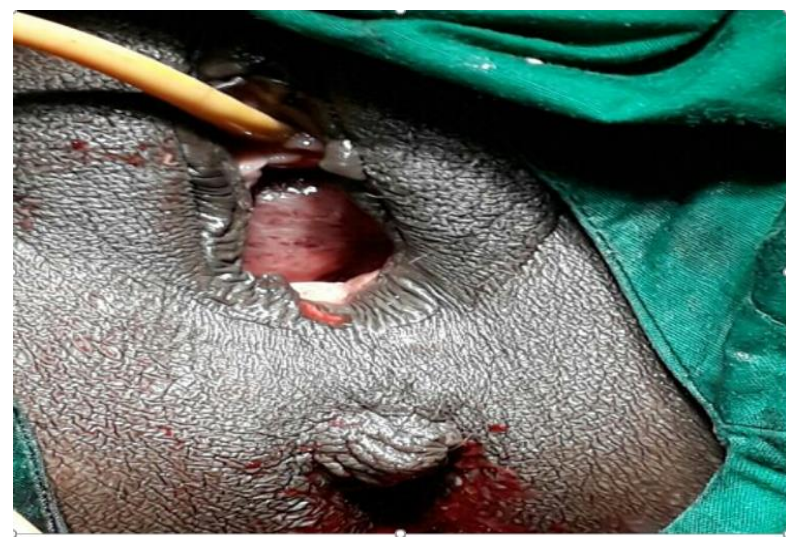

Figure 6: Uterus is pulled up after excision of fibroid, per vaginal view.

Uterus is pulled up in abdomen (Figure 7), as CT was suggestive of hydroureter and hydronephrosis, to avoid any injury to ureters while ligating pedicle, both pelvic ureters carefully traced till entry in bladder, by keeping ureters under direct vision abdominal hysterectomy with bilateral salpingectomy (Figure 8 and 9) is done. Weight of fibroid was $2 \mathrm{~kg}$. Patient received $1 \mathrm{PCV}$ transfusion intra operatively. Her post-operative period was uneventful. HPR confirmed leiomyoma.

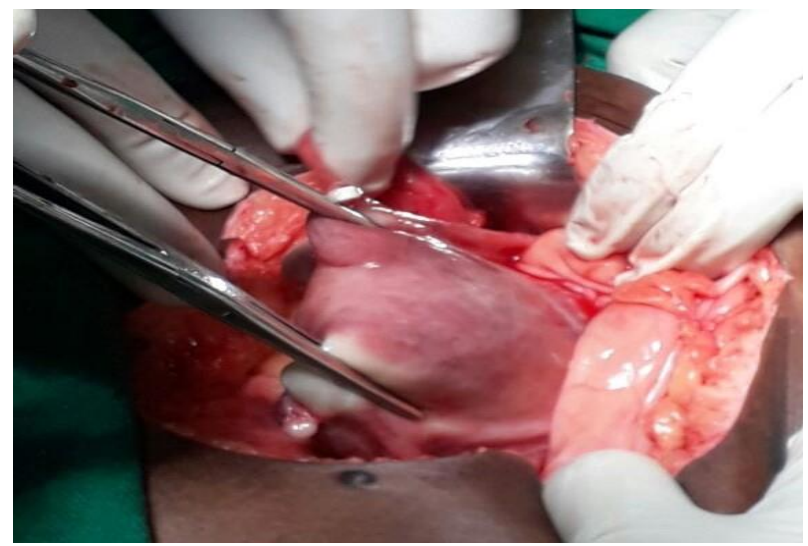

Figure 7: Uterus pulled up abdominally.

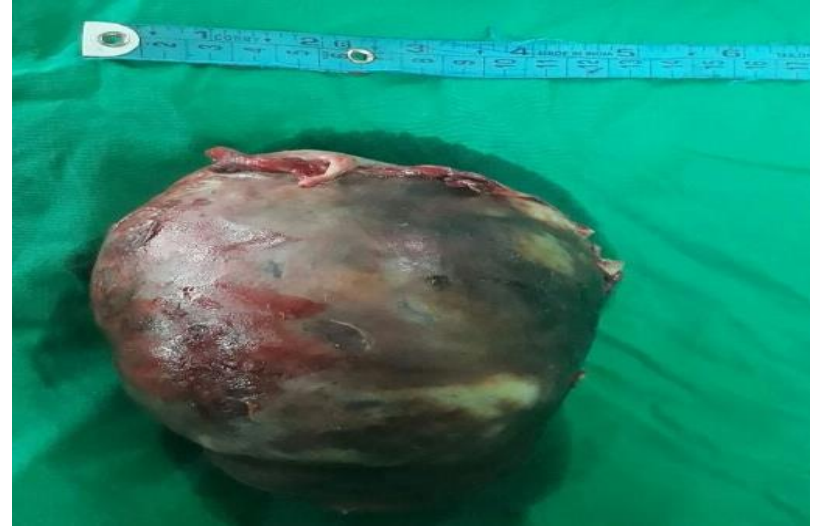

Figure 8: Excised pedunculated cervical leiomyoma.

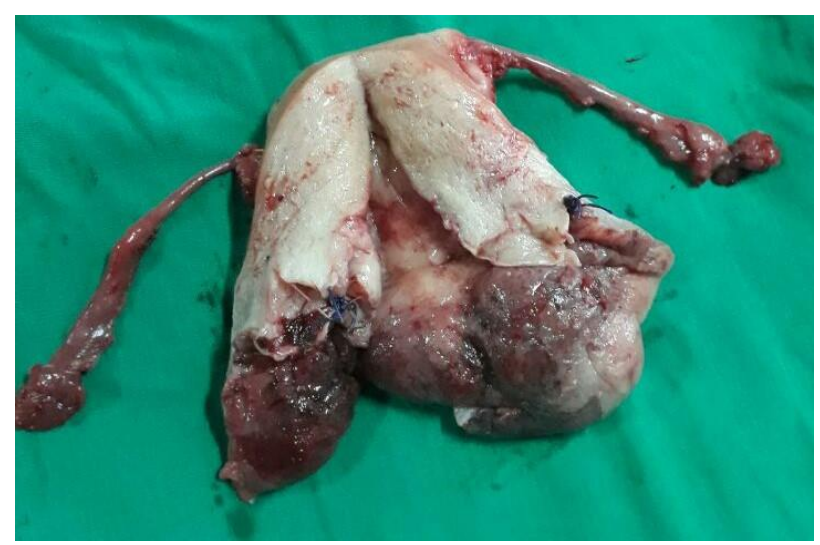

Figure 9: Specimen of uterus after excision of leiomyoma.

\section{DISCUSSION}

Cervical leiomyomas are extremely rare, and the incidence is reported at about $0.6 \%$ in total hysterectomy specimens. Cervix is mainly composed of involuntary smooth muscles superiorly and fibrous connective tissue inferiorly. ${ }^{4}$ Cervical leiomyomas can be categorized as extra cervical type (sub serosal location) and intracervical type (occur within the cervix). The complications of cervical leiomyomas include pressure effects on the bladder or urethra, degenerative phenomena, intermenstrual bleeding, pain (pelvic cramping), prolapse with infection and torsion. ${ }^{5}$ Probably this Leiomyoma arose from the smooth muscle and was expelled out and remained attached to the posterior lip of the cervix with thick pedicle. Huge cervical fibroid polyps are rare. The presentations of large cervical fibroid are reported as abdominal mass, incarcerated procidentia, uterine inversion, cervical malignancy etc. Fibroid arising from vaginal part of cervix may remain asymptomatic. If it is pedunculated, there may be sensation of something coming down or infected, foul-smelling discharges per vagina. ${ }^{5}$ The complications of cervical leiomyomas include pressure effects on the bladder or urethra, degenerative phenomena, intermenstrual bleeding, pain (pelvic cramping), prolapse with infection and torsion. A similar case is reported in recent literature by Dilip et al, 
from india, managed by abdomen vaginal approach. ${ }^{6}$ Massinde et al, from Tanzania reported a case of large cervical polyp with uterine prolapse in a 55 year old multiparous woman. ${ }^{7}$ Khalil et al, from Lebanon reported a case of giant cervical polyp in a sexually inactive nulliparous lady, Amesse et al, reported a case of huge cervical polyp in adolescence. 8,9 Most of the reported cases of giant or huge cervical polyp are found in perimenopausal women. Few similar cases reported where huge cervical fibroid polyp presentation has mimicked that of procidentia, cervical malignancy. ${ }^{10,11}$ Literature supports that most of these cases managed by polypectomy/vaginal myomectomy with or without hysterectomy. The management of cervical myoma is a real challenge to the gynecologists. Besides the excessive menstruation, severe anemia and propensity to infection, long standing pressure on neighboring structures like ureters causing hydronephrosis and acute renal failure have been reported with this myoma. Cervical leiomyoma may elongate, prolapse out the uterine cavity and present with emergency like retention of urine. Uterine artery embolization and laparoscopic-assisted uterine depletion of the myomas may precipitate the degeneration and prolapse of exiting cervical myoma. Route and type of surgery should be planned in advanced especially in nulliparous woman. Ben-Baruch et al, have studied the immediate and late outcomes and recommended vaginal myomectomy as the initial treatment of choice for prolapsed pedunculated submucous myoma, except in those cases in which other indications necessitate an abdominal approach. ${ }^{12}$ In recent times, hysteroscopic myomectomy can be preferred if the myoma is small and the pedicle is accessible. Regarding the need for hysterectomy in patients who have completed the family and not keen on preserving the uterus, the choice of route was analyzed by Benassi et al, It was found that vaginal route is preferable to abdominal route as the operatingtime, cost, postoperative fever, and need for analgesia are reported to be less without any significant difference in blood loss or other complications. ${ }^{13}$ In present case, a combined approach was used considering the confusion in diagnosis, large mass felt through the abdomen and inaccessibility of the pedicle of cervical myoma by a solitary vaginal route. In present case since the patient had completed her family and desired a definitive treatment. Authors opted for fibroid excision followed by hysterectomy. Thus, it appeared confusing initially, with careful evaluation, search of literature, and good clinical judgment, successful excision of mass was achieved.

\section{CONCLUSION}

Careful vaginal examination is mandatory to diagnose the cervical fibroid polyp as it may arise confusion with uterine inversion, uterine myxomatous polyp, cervical malignancy and 'en caul birth'. So, management depends on actual diagnosis and expertise decision. Large cervical fibroids are a very rare scenario and require an expert hand to operate them to avoid blood loss, prevent inadvertent injury to ureters or the bladder.

Funding: No funding sources

Conflict of interest: None declared

Ethical approval: Not required

\section{REFERENCES}

1. Bhatla N, Tumors of corpus uteri. In: Coats, J, eds. Principles of gynecology. $5^{\text {th }}$ ed. London: Arnold Publisher; 2001:407.

2. Drinville JS, Memarzadeh S. Benign disorders of the uterine corpus. In: De Cherney AH, Nathan L, eds. editors. Current obstetrics and gynaecologic diagnosis and treatment. $10^{\text {th }}$ ed. New York: Lange McGraw Hill; 2007:639-653.

3. Dutta DC. Benign lesions of the uterus. In: Text book of Gynaecology including contraception India. New Central Book Agency (P) Ltd. 2004;3:264.

4. Basnet N, Banerjee B, Badani U, Tiwari A, Raina A, Pokharel $\mathrm{H}$, et al. An unusual presentation of huge cervical fibroid. Kathmandu Univ Med J (KUMJ). 2005;3(2):173-4.

5. Suneja A, Taneja A, Guleria K, Yadav P, Agarwal N. Incarcerated procidentia due to cervical fibroid: an unusual presentation. Aus New Zeal J Obstet Gynaecol. 2003;43(3):252-3.

6. Dilip SA, Aher GS, Gavali U. Huge fibroid polyp. A case report. Sch J Med Case Rep. 2014;2(2):78-9.

7. Massinde AN, Mpogoro F, Rumanyika RN, Magona M. Uterine prolapsed complicated with giant cervical polyp. J Low Genit Tract Dis. 2012;16(1):64-5.

8. Khalil AM, Azar GB, Kaspar HG, Abu-Musa AA, Chararah IR, Seoud MA. Giant cervical polyp. A case report. J Reprod Med. 1996;41(8):619-21.

9. Amesse LS, Taneja A, Broxson E, Pfaff-Amesse J. Protruding giant cervical polyp in a young adolescent with a previous rhabdomyosarcoma. J Pediatr Adolesc Gynecol. 2002;15(5):271-7.

10. Yi KW, Song SH, Kim KA, Jung WY, Lee JK, Hur JY. Giant endocervical polyp mimicking cervical malignancy: primary excision and hysteroscopic resection. J Minim Invasive Gynecol. 2009;16(4):498500.

11. Harrison AO. Prolapsed giant cervical fibroid polyp mimicking procidentia- aftermath of traditional therapy for fibroids: A case report and review of the literature. Open Sci J Clin Med. 2014;2(1):15-8.

12. Ben-Baruch G, Schiff E, Menashe Y, Menczer J. Immediate and late outcome of vaginal myomectomy for prolapsed pedunculated submucous myoma. Obstet Gynecol. 1988;72:858-61.

13. Benassi L, Rossi T, Kaihura CT, Ricci L, Bedocchi L, Galanti B, et al. Abdominal or vaginal hysterectomy for enlarged uteri: a randomized clinical trial. Am J Obstet Gynecol. 2002;187(6):1561-5.

Cite this article as: Khade SA, Jadhav B, Raut R. Huge cervical pedunculated leiomyoma with uterine prolapse: a case report. Int J Reprod Contracept Obstet Gynecol 2019;8:772-5. 